\section{A) Check for updates}

Cite this: Dalton Trans., 2020, 49 11354

\title{
Magnesium hydrides bearing sterically demanding amidinate ligands: synthesis, reactivity and catalytic application $\uparrow$
}

\begin{abstract}
Clare Bakewell (D)
The synthesis and characterisation of a series of magnesium complexes bearing sterically demanding amidinate ligands is reported; this includes magneisum amides (1a and $\mathbf{1} \mathbf{b})$, hydrides ( $\mathbf{3} \mathbf{a}$ and $\mathbf{3} \mathbf{b})$ and alkyl complexes $(\mathbf{2} \mathbf{b})$. The solid and solution state behaviour of the complexes has been investigated using single crystal $X$-ray diffraction and NMR spectroscopy, revealing the magnesium hydrides to exist as dimers in the solid state, dispite the sterically demanding ligand systems and showing a degree of monomeric character in solution. The stoichiometric and catalytic activity of the amidinate complexes were investigated, with the complexes found to efficiently mediate both the hydroamination of $N_{1} N^{\prime}$-diisopropylcarbodiimide and the Tishchenko reaction. The metal hydrides are highly reactive towards coordinating substrates, showing a significant increase in catalytic rate compared with more ubiquitous $\beta$-diketiminate magnesium hydrides.
\end{abstract}

Received 17th July 2020, Accepted 3rd August 2020

DOI: $10.1039 / d 0 d t 02523 b$ rsc.li/dalton species has also been possible through the use of ligand systems with high coordination numbers (Fig. 1: B and C). ${ }^{7,8}$ These compounds have been shown to be catalytically active, for instance $\mathbf{C}$ has is a competent catalyst for both olefin

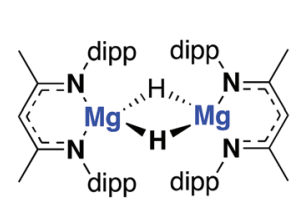

(A)

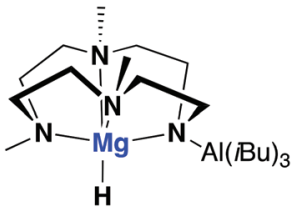

(B) 2 metals. In hydroboration, hydroamination and hydrosilation reactions, magnesium hydrides are often identified as the active catalytic species. Despite their common use and application in catalysis, examples of discrete, stable and isolatable $\mathrm{Mg}-\mathrm{H}$ species remain relatively rare. ${ }^{2,3}$ Two-coordinate $\beta$-diketiminate ligands have been shown to support magnesium hydrides, such as $\mathbf{A}$, which is stable towards Schlenk redistribution at room temperature and exists as a dimer. ${ }^{4} \mathbf{A}$ has been widely employed in catalysis, either used directly or formed in situ, for reactions such as the hydroboration of aldehydes and ketones and the reduction of $\mathrm{CO}$ with phenylsilane. ${ }^{5,6}$ The isolation of terminal magnesium hydride

University College London, Department of Chemistry, 20 Gordon Street, London WC1H OAJ, UK. E-mail: c.bakewell@ucl.ac.uk

$\dagger$ Electronic supplementary information (ESI) available. CCDC 2016829-2016833. For ESI and crystallographic data in CIF or other electronic format see DOI: 10.1039/d0dt02523b

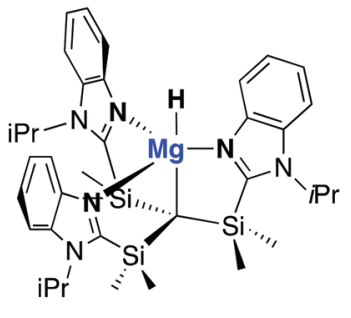

(C)

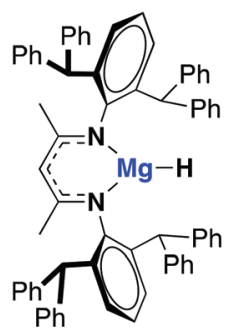

(D)

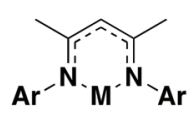

$\beta$-diketiminate

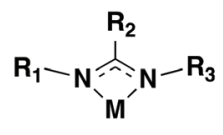

amidinate

Fig. 1 Top: Examples of monomeric and dimeric magnesium hydrides used in catalysis. Bottom: general structure of $\beta$-diketiminate and amidinate ligands. 
hydrosilylation and the hydroboration of carbodiimides. ${ }^{7}$ Sterics have been used to favour the formation of monomeric, low-coordinate compounds leading to the isolation of a 'super bulky' $\beta$-diketiminate magnesium hydride complex, $\mathbf{D}$. However, the increased steric profile rendered the complex relatively unreactive, even towards water. $^{9}$ In contrast to $\beta$-diketiminate ligands, the two-coordinate amidinate ligand framework has a significantly different steric profile, with the 4-membered ring directing the nitrogen substituents further from the metal centre. Amidinates also offer greater potential for structural modification due to the modular way in which they can be synthesised. Both symmetric and asymmetric ligand systems can be easily accessed, as well as modification of the bridgehead carbon substituent (guanidinate where bridgehead $=\mathrm{NR}_{2}$ ). Recently, examples of guanidinate and amidinate ligand frameworks bearing 'super bulky' aryl groups have been developed. In 2014 Fortier and co-workers reported the synthesis of a super bulky guanidinate ligand and it's coordination with group 1 metals, as well as with iron to stabilise a terminal $\mathrm{Fe}(\mathrm{Iv})$ nitride species $\left(\left(\mathrm{Ar}^{*} \mathrm{~N}\right)_{2} \mathrm{RCH}\right.$ where $\mathrm{Ar}^{*}=$ 2,6-bis(diphenylmethyl)-4-tert-butylphenyl and $\mathrm{R}=\mathrm{NC}$ $\left.(t \mathrm{Bu})_{2}\right) .^{10,11}$ Both Jones and Harder have more recently developed amidinate analogues with bulky 2,6-(diphenylmethyl) substituents, coordinating them to magnesium and strontium amides. ${ }^{12,13}$ Using an asymmetric ligand, where $R_{1}=2,6$ (diphenylmethyl) and $\mathrm{R}_{2}=2,6$-(diisopropyl), Jones was also able to isolate both magnesium and strontium hydrides. These represent the first examples of group 2 hydrides stabilised by amidinate (or guanidinate) ligands. The reactivity of this new class of metal hydride complex has yet to be investigated, but the more strained and open coordination environment at the metal centre present interesting distinctions from the more ubiquitous $\beta$-diketiminate systems. Therefore diversifying this family of magnesium hydrides and exploring their potential in catalysis is of interest. Herein, the synthesis and reactivity of two novel magnesium hydride complexes stabilised by a symmetric and asymmetric amidinate ligand is discussed.

\section{Results and discussion}

Two ligand systems were chosen to be the focus of this study, $\mathbf{L} \mathbf{H}^{1}$ and $\mathbf{L} \mathbf{H}^{2}$, both of which were synthesised by modifying literature procedures (Fig. S1 $\dagger$ ). Magnesium amide complexes 1a and $\mathbf{1 b}$ were then prepared by reaction of pro-ligand $\mathbf{L H}^{\mathbf{1}}$ (1a) or $\mathbf{L H}^{2}$ (1) with one equivalent of the magnesium precursor $\mathrm{Mg}\left[\mathrm{N}\left(\mathrm{SiMe}_{3}\right)_{2}\right]_{2}$ in toluene (Scheme 1). Compound $\mathbf{1 a}$ formed after stirring at room temperature for $5 \mathrm{~h}$, whereas $\mathbf{1 b}$ required heating at $110{ }^{\circ} \mathrm{C}$ for 3 days. Signals in the ${ }^{1} \mathrm{H}$ NMR spectrum at $\delta 0.02$ and $\delta-0.15 \mathrm{ppm}$ (1a and $\mathbf{1 b}$ ) corresponding to eighteen protons $\left(-\mathrm{N}\left(\mathrm{SiMe}_{3}\right)_{2}\right)$ confirm the formation of the monoligated product. Crystals suitable for single crystal X-ray diffraction were isolated and the solid state structures of both $1 \mathrm{a}$ and 1b show the expected three-coordinate magnesium centre, with key bond lengths and angles shown in Fig. 2. In both

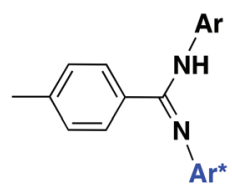

$\operatorname{Ar}=\operatorname{Ardipp}^{\text {dit }}\left(\mathbf{L H}^{1}\right) ; \operatorname{Ar}^{*}\left(\mathbf{L H}^{2}\right)$
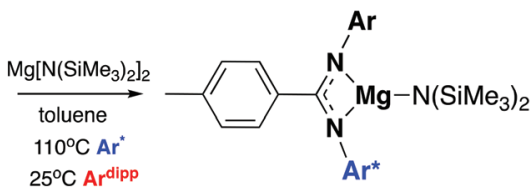

$\operatorname{Ar}=\operatorname{Ardipp}(1 a) ; A r^{*}(1 b)$

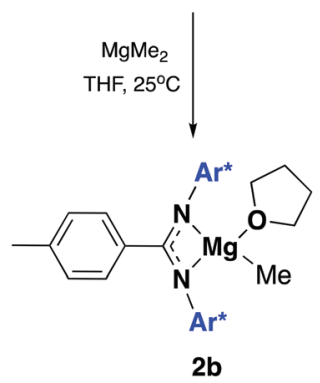

Scheme 1 Synthetic procedure for the formation of compounds $1 \mathrm{a}, 1 \mathrm{~b}$ and $2 \mathrm{~b}$.

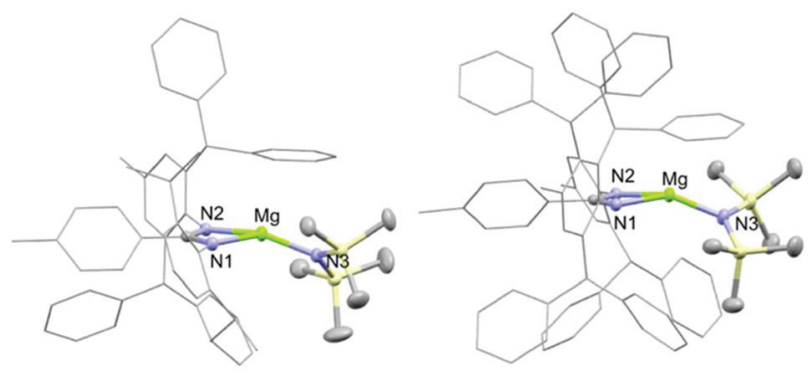

Fig. 2 Solid state structure of $1 \mathrm{a}$ and $1 \mathrm{~b}$. Selected bond lengths $(\AA \AA)$ and angles $\left(^{\circ}\right.$ ). 1a: Mg-N1 2.088(1); Mg-N2 2.072(1); Mg-N3 1.967(1); N1Mg-N2 64.7; N1-C-N2 113.3. 1b: Mg-N1 2.115(12); Mg-N2 2.087(2); Mg-N3 1.967(3); N1-Mg-N2 64.3; N1-C-N2 113.2.

compounds there are significant deviations from linearity, with the amide group bent away from the $\mathrm{N}-\mathrm{Mg}-\mathrm{N}$ plane by $154.8^{\circ}(\mathbf{1 a})$ and $151.7^{\circ}(\mathbf{1 b})$. This is due to additional stabilising interactions between one of the ligand based aryl groups with the magnesium centre (Mg...Ar; 1a: 2.840(1); 1b: 2.767(2)). Other magnesium precursors were also explored; reaction of $\mathbf{L H}^{2}$ with $\mathrm{MgMe}_{2}$ in toluene was hindered by the limited solubility of the magnesium precursor, however in tetrahydrofuran (THF) formation of the THF adduct (2b) was facile.

Compounds $\mathbf{1 a}$ and $\mathbf{1 b}$ were subsequently reacted with phenylsilane in toluene at $80{ }^{\circ} \mathrm{C}$ for 16 hours and at $115{ }^{\circ} \mathrm{C}$ for three days, respectively (Scheme 2). The ${ }^{1} \mathrm{H}$ NMR spectra reveal distinctive signals at $\delta 3.64 \mathrm{ppm}$ (3a) and $\delta 5.03 \mathrm{ppm}$ (3b) which correspond to the newly formed magnesium hydrides $(\mathrm{Mg}-\mathrm{H})$. The $\mathrm{Mg}-\mathrm{H}$ signal in 3a matches well with a closely related complex reported by Jones and co-workers. ${ }^{13}$ However, the $\mathrm{Mg}-H$ NMR shift of $\mathbf{3 b}$ is significantly further downfield, with other examples of downfield ( $>\delta 4.5 \mathrm{ppm}$ ) $\mathrm{Mg}-H$ signals relating to structurally characterised examples of terminal magnesium hydrides (Fig. S2†). ${ }^{4-9,13-22}$ Compound $3 \mathbf{b}$ can also be made using a more facile synthetic route, reacting $\mathbf{L H}^{2}$ 

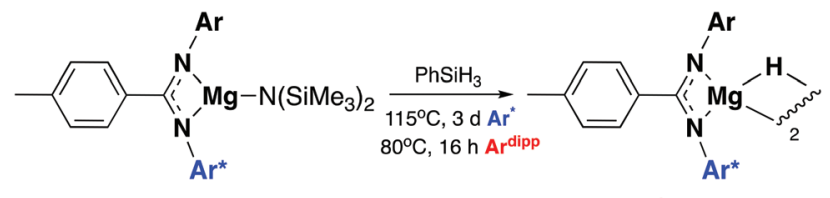

$\operatorname{Ar}=\operatorname{Ar}^{\text {dipp }}(1 a) ; \operatorname{Ar}^{*}(1 b)$

$\operatorname{Ardipp}^{\text {(3a); }} \operatorname{Ar}^{*}(3 b)$
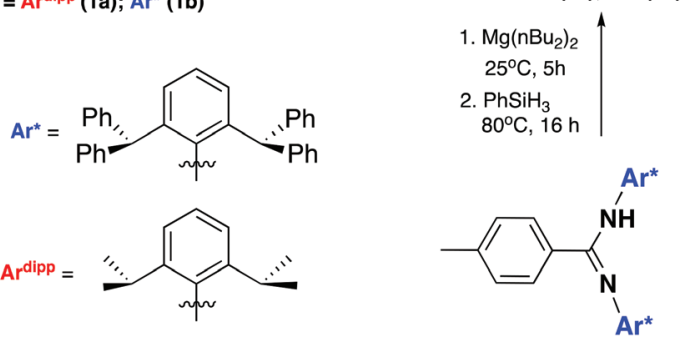

Scheme 2 Synthetic procedure for the formation of compounds 3a and $3 \mathrm{~b}$.

with dibutyl magnesium to form $\mathbf{L}^{2} \mathbf{M g}(n \mathrm{Bu})$, which was not isolated but further reacted with phenylsilane under milder conditions ( $80{ }^{\circ} \mathrm{C}, 16$ hours) to form $3 \mathbf{b}$ in good yield (58\%). Attempts to react $\mathbf{2 b}$ with phenylsilane under a variety of conditions failed to yield any magnesium hydride product. Crystals of $\mathbf{3 a}$ and $\mathbf{3 b}$ suitable for single crystal XRD were isolated from concentrated $\mathrm{C}_{6} \mathrm{D}_{6} /$ hexane or $\mathrm{C}_{6} \mathrm{D}_{6}$ solutions, however both samples repeatedly co-crystallised with a hydroxide impurity (modelled as 3a 31\%, 3b 24\%, see ESI $\dagger$ ). This occurred despite negligible hydroxide content in the sample (3a 3\% in ${ }^{1} \mathrm{H}$ NMR; 3b none observed in ${ }^{1} \mathrm{H}$ NMR $\$$ ), indicating that minor hydroxide impurities crystallise out of solution preferentially. Nevertheless, the structures clearly show that both compounds are dimeric in the solid state, in contrast to the $\beta$-diketiminate magnesium hydride bearing the same nitrogen substituents (2,6-(diphenylmethyl)), which was monomeric. ${ }^{9}$ Whilst the presence of the hydroxide prevents comparison of the $\mathrm{Mg}-\mathrm{H}$ bond lengths, it is still possible to compare the structures of $\mathbf{3 a}$ and $\mathbf{3} \mathbf{b} . \mathbf{3} \mathbf{b}$ is significantly more contorted than 3a, with the two $\mathrm{N}-\mathrm{Mg}-\mathrm{N}$ planes twisted at approximately $49^{\circ}$ from one another. The hydride/hydroxide ligands lay in a third orientation (Fig. S14 ${ }^{\dagger}$ ), whereas in 3a they are approximately orthogonal to the $\mathrm{N}-\mathrm{Mg}-\mathrm{N}$ plane. The dimeric structure of $\mathbf{3 b}$ is somewhat surprising given it's markedly different $\mathrm{Mg}$ $H$ NMR shift. Therefore, in order to determine if $\mathbf{3 b}$ maintained its dimeric structure in solution, a Diffusion Ordered NMR spectroscopy (DOSY) experiment was conducted and the diffusion coefficient and hydrodynamic radius compared with 1b $\left(0.01 \mathrm{M}\right.$ in $\mathrm{C}_{6} \mathrm{D}_{6}, \mathbf{1 b}: 4.64 \times 10^{-10} \mathrm{~m}^{2} \mathrm{~s}^{-1}, 1950 \AA^{3}$; 3b: $4.04 \times$ $10^{-10} \mathrm{~m}^{2} \mathrm{~s}^{-1}, 2950 \AA^{3}$, Table $\left.\mathrm{S} 1 \dagger\right)$. Compound $3 \mathbf{b}$ is approximately 1.5 times the volume of $\mathbf{1 b}$, which due to the sterically demanding amide co-ligand can only exist as a monomer. Conversely, 3a has only a slightly larger solution volume than 1a (1a: $4.95 \times 10^{-10} \mathrm{~m}^{2} \mathrm{~s}^{-1}, 1600 \AA^{3}$; 3a: $4.72 \times 10^{-10} \mathrm{~m}^{2} \mathrm{~s}^{-1}$,

\$Crystals of $\mathbf{3 b}$ were grown from a concentrated $\mathrm{C}_{6} \mathrm{D}_{6}$ solution in a sealed YT NMR tube which did not indicate the presence of any $\mathrm{Mg}-\mathrm{OH}$ side product in the ${ }^{1} \mathrm{H}$ NMR spectrum.

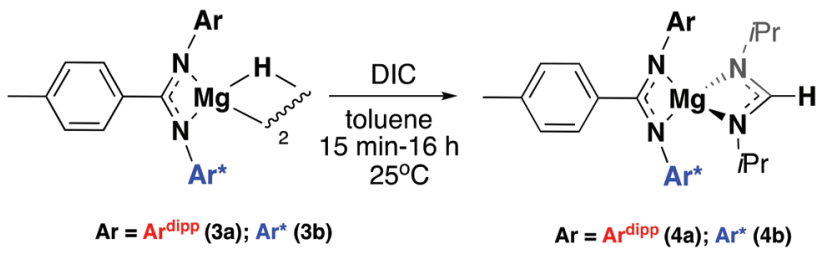

Scheme 3 Synthetic procedure for the formation of compounds $4 a$ and $\mathbf{4 b .}$

$1850 \AA^{3}$ ). This suggests $3 \mathbf{b}$ has significant dimeric character in solution, whereas $\mathbf{3 a}$ appears to tend toward a monomer. This may be related to the asymmetric ligand rendering the dimer less stable. The stable formation of $\mathbf{3 b}$ is in contrast to attempts to isolate the analogous strontium hydride compound utilising a very similar ligand system $(i \operatorname{Pr}$ versus Me $) .{ }^{12}$ Here, the transient formation of the $\mathrm{Sr}-\mathrm{H}$ species is proposed, followed by rapid deprotonation of an acidic methine proton $(\mathrm{CHPh})$ in the ligand framework to yield an intramolecular $\mathrm{Ph}_{2}$ (aryl)C $\mathrm{C}^{-}$anion. Isolation of this new series of low-coordinate magnesium amide and magnesium hydride complexes presents the opportunity to investigate their stoichiometric and catalytic reactivity. Addition of one equivalent of $N, N^{\prime}-$ diisopropylcarbodiimide to $\mathbf{3 a}$ in $\mathrm{C}_{6} \mathrm{D}_{6}$ led to the facile formation of the $\mathrm{Mg}-\mathrm{H}$ insertion product $4 \mathbf{a}$ (Scheme 3). The same reaction with compound $\mathbf{3 b}$ proceeded slower, but after 16 hours at room temperature the distinctive loss of the hydride resonance was observed along with the formation of a new singlet at $7.86 \mathrm{ppm}$ corresponding to the formamidinate methine proton (4b, Fig. S3 $\dagger$ ). Both compounds $\mathbf{4 a}$ and $\mathbf{4 b}$ could be characterised in situ, however their solution stability was poor. Upon standing in a J. Youngs NMR tube over 2 days, a significant amount of decomposition was observed in both samples, in addition to liberation of the protonated ligand.§ Despite their relative instability, the reactivity of $\mathbf{3 a}$ and $\mathbf{3} \mathbf{b}$ towards $N, N^{\prime}$-diisopropylcarbodiimide suggests they may be active catalysts for carbodiimide functionalisation. In 2016, Hill and co-workers reported the first example of the catalytic hydroboration of a carbodiimides. ${ }^{23}$ These reactions employed a $\beta$-diketiminate magnesium butyl complex as a pre-catalyst and propose magnesium hydride $\mathbf{A}$ to be the active catalytic species. Compounds $\mathbf{3} \mathbf{a}$ and $\mathbf{3} \mathbf{b}$ were found to catalyse the hydroboration of $N, N^{\prime}$-diisopropylcarbodiimide with HBpin (4,4,5,5-tetramethyl-1,3,2-dioxaborolane) with surprisingly good efficiencies (Table 1). At $60^{\circ} \mathrm{C}$ using 3a, 86\% conversion to the singly reduced hydroboration product was achieved after 4 hours. This was reduced to $1.5 \mathrm{~h}$ when the reaction temperature was increased to $80{ }^{\circ} \mathrm{C}$, approximately four times faster than the related $\beta$-diketiminate system. Compound 3a was also found to catalyse the reaction at room temperature, albeit slowly, with $19 \%$ conversion after $24 \mathrm{~h}$. Compound $\mathbf{3 b}$ was significantly slower, requiring $5 \mathrm{~h}$ at $80{ }^{\circ} \mathrm{C}$ to reach high conver-

$\S$ These reactions have been attempted multiple times with additional drying measures put in place, but always yielded decomposition products. The unstable molecule may be reacting intramolecularly or with solvent. 
Table 1 Catalytic hydroboration of $N, N^{\prime}$-diisopropylcarbodiimide

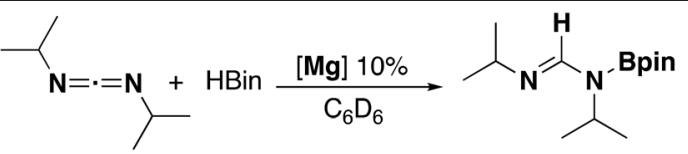

\begin{tabular}{llll}
\hline Complex & $t(\mathrm{~h})$ & $T\left({ }^{\circ} \mathrm{C}\right)$ & Conversion $(\%)$ \\
\hline 1a & 24 & 25 & 13 \\
1a & 1.5 & 80 & 90 \\
3a & 24 & 25 & 19 \\
3a & 4 & 60 & 86 \\
3a & 1.5 & 80 & 86 \\
1b & 5 & 80 & 91 \\
3b & 24 & 60 & 80 \\
3b & 5 & 80 & 90
\end{tabular}

Reaction conditions: $[$ HBpin $]=[\mathrm{DIC}]=0.4 \mathrm{M}$ in $\mathrm{C}_{6} \mathrm{D}_{6}$. Conversions determined by ${ }^{1} \mathrm{H}$ NMR spectroscopy.

sion, in line with its reduced activity towards $N, N^{\prime}$-diisopropylcarbodiimide. The reduced reactivity of $\mathbf{3 b}$ relates to the increased sterics of $\mathbf{3 b}$ versus $\mathbf{3} \mathbf{a}$, in addition to higher retention of dimeric character in solution, rendering the magnesium-hydride bond less accessible towards substrates. In all cases, addition of a second equivalent of HBpin did not lead to formation of the doubly reduced product. The related amide compounds $\mathbf{1 a}$ and $\mathbf{1} \mathbf{b}$ were also shown to be efficient pre-catalysts towards the hydroboration reaction, with identical reactivities to their hydride analogues. More detailed kinetic analysis was conducted at $80{ }^{\circ} \mathrm{C}$, with ${ }^{1} \mathrm{H}$ NMR spectra collected at regular time intervals during the reaction (Fig. 3). The rate of consumption of $N, N^{\prime}$-diisopropylcarbodiimide and HBpin was consistent over time, with the rate not dropping significantly as the reaction progressed. The same reactivity profile was observed for $\mathbf{1} \mathbf{a}-\mathbf{b}$ and $\mathbf{3} \mathbf{a}-\mathbf{b}$ and the data did not fit pseudo first- or second-order reaction kinetics (Fig. S7 and $8 \dagger$ ).

The reactivity of $\mathbf{3} \mathbf{a}$ and $\mathbf{3} \mathbf{b}$ towards terminal alkenes was also tested. Recently, a variety of alkene substrates have been

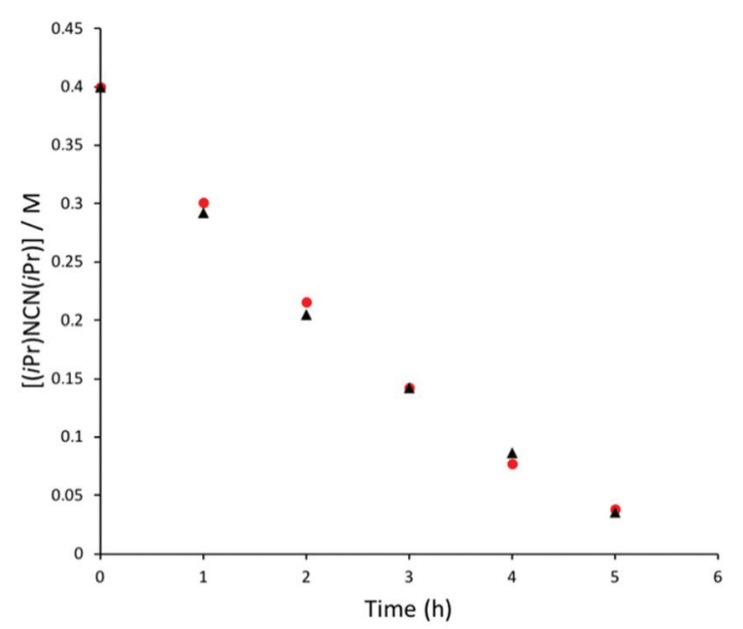

Fig. 3 Plot of [(iPr)NCN(iPr)] versus time for $\mathbf{1 b}$ (black triangles) and $3 \mathbf{b}$ (red circles). shown to insert into the $\mathrm{Mg}-\mathrm{H}$ bond of $\mathbf{A}$, at high temperature on the day timescale. ${ }^{24}$ However, even with prolonged heating, no reaction was observed for $\mathbf{3 a}$ or $\mathbf{3} \mathbf{b}$ with either 1-hexene or styrene. Conversely, 1a and $\mathbf{3 a}$ were found to undergo facile reaction with the terminal alkyne phenylacetylene. Reaction of one equivalent of phenylacetylene with 1a in benzene- $d_{6}$ led to the formation of dehydrogenation product 5a in less than 15 minutes. The characteristic $\mathrm{Mg}-\mathrm{N}\left(\mathrm{SiMe}_{3}\right)_{2}$ peak at -0.03 was seen to disappear, and bis(trimethylsilyl)amine was observed to form. Reaction of $\mathbf{3 a}$ with one equivalent of phenylacetylene also saw the formation of 5a, with loss of the magnesium hydride signal and dihydrogen formation observed. An intermediate species was also seen to form during the reaction but it could not be identified (Fig. S4 $\dagger$ ). Crystals of $\mathbf{5} \mathbf{a}$ formed readily from a saturated benzene- $d_{6}$ solution and were analysed by single crystal X-ray diffraction. The complex crystallised as a dimer in the $P \overline{1}$ space group, with the two N-Mg-N fragments slightly distorted from one another in one plane and the phenyl acetylides ligands lying orthogonal (Fig. 4). The phenyl acetylides lie slightly asymmetrically between the two magnesium centres, with an Mg1-C62 $\equiv \mathrm{C}$ bond angle of $133.4^{\circ}$ and a $\mathrm{Mg} 2-\mathrm{C} 62 \equiv \mathrm{C}$ bond angle of $143.6^{\circ}$. A series of related compounds based on $\beta$-diketiminate magnesium and calcium complexes has been previously reported by Hill and co-workers, however these show significantly more distorted acetylides units. ${ }^{25}$ As with $\mathbf{4 a}$, all attempts to isolate a sample of $\mathbf{5 a}$ led to rapid product decomposition indicating $\mathbf{5 a}$ has poor stability. It is likely that the steric influence of the ligand in 5a prevents additional stabilising interactions between the alkyne groups and the magnesium centres. Compounds $\mathbf{1 b}$ and $\mathbf{3 b}$ also react with phenylacetylene, though the reaction is slower than with $\mathbf{1 a}$ and $\mathbf{3 a}$. Reaction of $\mathbf{1 b}$ with a slight excess of phenylacetylene in benzene- $d_{6}$ led to the slow formation of $\mathbf{5 b}$ over 16 hours at room temperature. Again the characteristic loss of the $\mathrm{Mg}-\mathrm{N}\left(\mathrm{SiMe}_{3}\right)_{2}$ peak at -0.15 was observed with concomitant formation of bis(trimethylsilyl) amine. Reaction of $\mathbf{3 b}$ under the same conditions showed negligible product formation, however heating for two hours at $80^{\circ} \mathrm{C}$ led to the complete and clean formation of compound $\mathbf{5 b}$. Analysis by ${ }^{1} \mathrm{H}$ NMR also showed the concomitant formation of styrene, as confirmed against an independent sample, and unlike reaction with $\mathbf{3 a}$ no liberation of dihydrogen was observed (Fig. S5†). This strongly indicates that the formation of 5b goes via a magnesium alkenyl intermediate, formed through insertion of the alkyne into the magnesium hydride bond (Scheme 4). This intermediate can then react with a second equivalent of phenylacetyene, forming $\mathbf{5 b}$ and liberating styrene. However, no intermediate species were detected by ${ }^{1} \mathrm{H}$ NMR during the course of the reaction. 1 Addition of excess phenylacetylene to $\mathbf{5 a}$ or $\mathbf{5} \mathbf{b}$ in benzene- $d_{6}$ did not lead to the formation of any stoichiometric or catalytic dimerization products and at elevated temperatures only ligand protonation was

ๆ Repeated attempts to collect single crystal data on $\mathbf{5 b}$ were unsuccessful due weakly diffracting samples. 

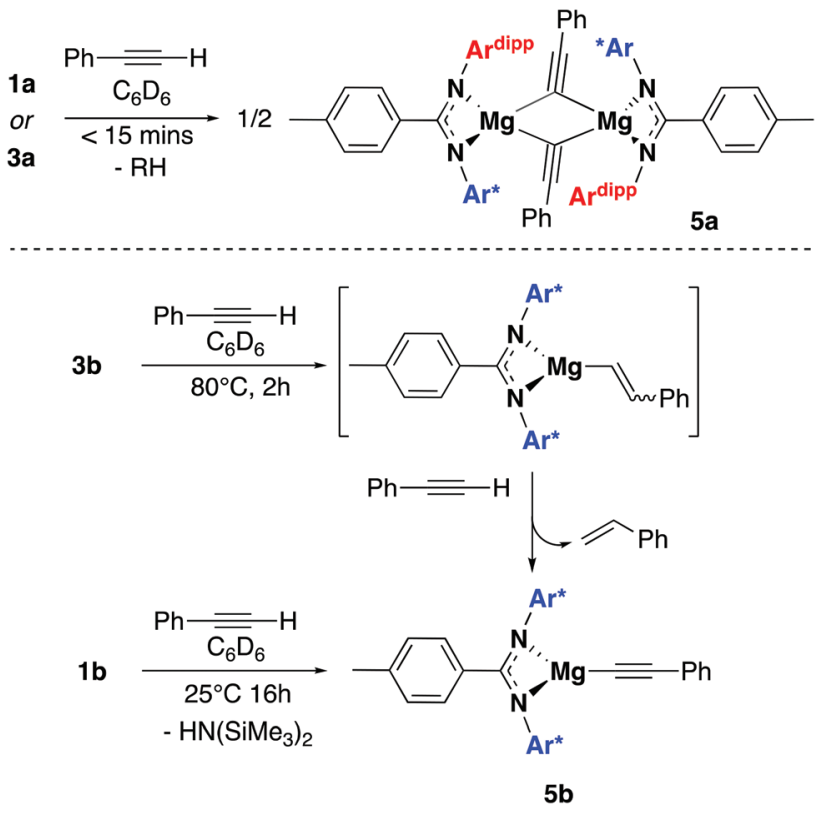

Scheme 4 Top: Synthetic procedure for the formation of $5 \mathrm{a}$. Bottom: two synthetic routes to $5 \mathbf{b}$.

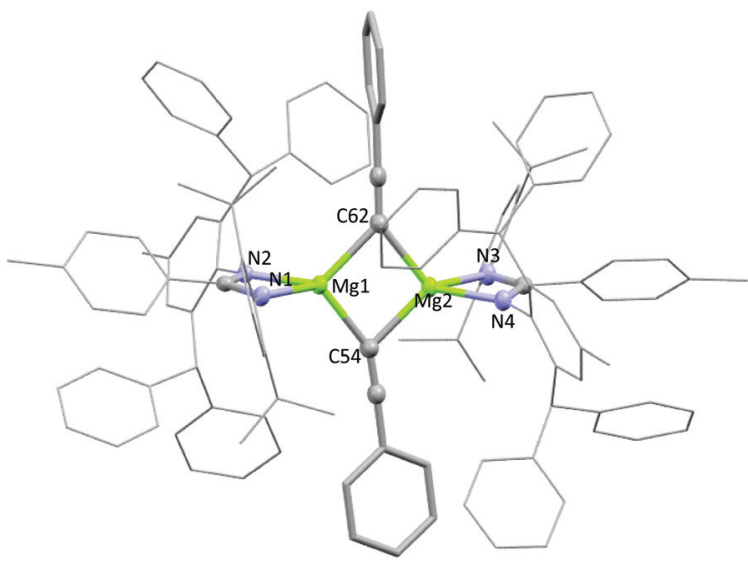

Fig. 4 Solid state structure of compound $5 \mathrm{a}$. Selected bond lengths ( $(\AA)$ and angles $\left({ }^{\circ}\right.$ ): Mg1-N1 2.042(1); Mg1-N2 2.054(1); Mg1-C54 2.168(2), Mg1-C62 2.190(2); N1-Mg1-N2 65.8; C54-Mg1-C62 97.1.

observed. Hill and co-workers also observe that $\beta$-diketiminate magnesium species were deprotonated in the presence of excess phenylacetylene at elevated temperatures. ${ }^{25}$

Last year, Rueping and co-workers reported the first example of the magnesium catalysed hydroboration of a series of terminal and internal alkynes. ${ }^{26}$ Dibutyl magnesium $\left(\mathrm{MgBu}_{2}, 10 \mathrm{~mol} \%\right)$ was found to form exclusively the $E$-product in high yields after $18 \mathrm{~h}$ at $60{ }^{\circ} \mathrm{C}$. Conversion was seen to be lower in the presence of $\beta$-diketiminate ligands. The isolated compounds $\mathbf{1 a}, \mathbf{1 b}$ and $\mathbf{3 b}$ were all found to catalyse the hydroboration of terminal alkynes, in all cases yielding the same anti-Markovnikov $E$-product. Using $\mathbf{1 a}$ and $\mathbf{1 b}(10 \mathrm{~mol} \%$ in benzene- $d_{6}$ ), a small amount of conversion was observed at
$25{ }^{\circ} \mathrm{C}$ after 4 days, $6 \%$ and $26 \%$ respectively. However, at $80{ }^{\circ} \mathrm{C}$ high conversions were reached within 16 h (86 and 88\% after 16 hours). The magnesium hydrides $\mathbf{3 a}$ and $\mathbf{3 b}$ were found to catalyse the hydroboration reactions at near identical rates (Table SX $\dagger$ ). When analysing the ${ }^{1} \mathrm{H}$ NMR spectrum of the catalytic mixture of $\mathbf{3 b}$ after 16 hours at $80{ }^{\circ} \mathrm{C}$ free ligand was observed, suggesting loss of the ligand during catalysis. Though this is not clearly observed is the other compounds, the minimal difference in rate observed between the four compounds bearing two different ligand systems, suggests that the ligand does not remain bound during catalysis and that the true active species is a magnesium centred organometallic generated in situ through reaction with phenylacetylene and HBpin. Previous observations regarding ligand protonation in the presence of excess phenylacetylene support this argument. Comparable rates with Rueping's system suggests the presence of a common catalytically active species. Recent work by Thomas and co-workers has highlighted hidden boron containing species to be active catalysts in 'metal catalysed' alkene and alkyne hydroboration reactions. ${ }^{27}$ The nature of the active catalyst in this and related systems is the subject of ongoing investigation.

Attempts to isolate alkoxides derivatives of $\mathbf{L H}^{1}$ and $\mathbf{L H}^{2}$ were also investigated. However, the reaction of a variety of alcohols with 1a and $\mathbf{1 b}$ only led to protonolysis of the ligand. 3b was instead reacted with benzaldehyde: addition of 1 equivalent of benzaldehyde to $\mathbf{3 b}$ in $\mathrm{C}_{6} \mathrm{D}_{6}$ led to the facile formation of the alkoxide product $\mathbf{6 b}$ (Scheme 5 , top). In the presence of an excess of benzaldehyde a dark orange solution was seen to form with analysis by ${ }^{1} \mathrm{H}$ NMR spectroscopy revealing the formation of the Tishchenko dimerization product, benzyl benzoate (Scheme 5, bottom). At $1 \mathrm{~mol} \%$ catalyst loading $3 \mathbf{b}$ catalysed a $1 \mathrm{M}$ solution of benzaldehyde in $\mathrm{C}_{6} \mathrm{D}_{6}$ to $72 \%$ conversion in 10 minutes. After 1 hour this has increased to 89\% conversion. Coles and co-workers have previously shown related magnesium amides and alkoxides to be efficient catalysts for the Tishchenko reaction, but this is the first example of a magnesium hydride compound being used as a precatalyst. $^{28,29}$ Compound $\mathbf{1 b}$ was also found to be catalytically active towards the dimerization of benzaldehyde, with only trace amounts of starting material remaining after 10 minutes under the same reaction conditions which is significantly

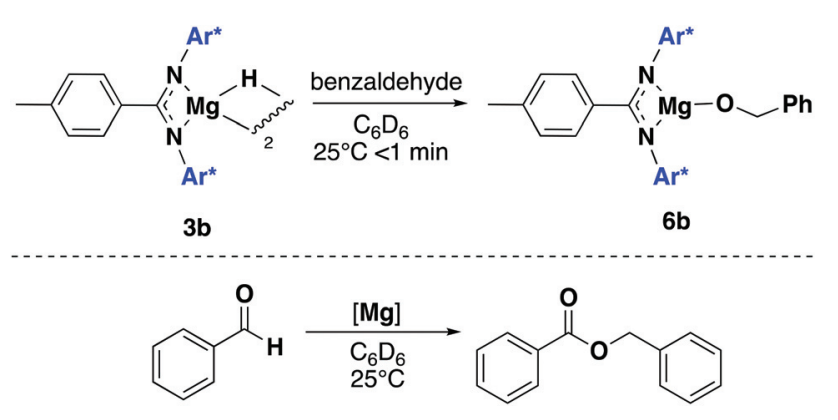

Scheme 5 Top: synthetic procedure for the formation of $6 \mathrm{~b}$. Bottom: tischenko reaction catalysed by $1 \mathrm{~b}$ and $3 \mathrm{~b}$. 
faster than the previously reported magnesium amides (95\% yield after $3 \mathrm{~h}$ ). Interestingly, upon addition of benzaldehyde to $\mathbf{1 b}$, the solution remained colourless, suggesting both $\mathbf{1 b}$ and $\mathbf{3 b}$ proceed via different catalytic intermediates. Attempts to react both 1a, 3a and magnesium hydride $\mathbf{A}$ with benzaldehyde led some initial unidentified reaction occurring, but no benzyl benzoate formation was observed.

\section{Conclusions}

A series of novel magnesium amidinate complexes has been synthesised and fully characterised, including two new rare examples of stable magnesium hydrides ( $\mathbf{3} \mathbf{a}$ and $\mathbf{3 b}$ ). The catalytic activity of these complexes has been investigated, with compounds $\mathbf{1} \mathbf{a}-\mathbf{b}$ and $\mathbf{3} \mathbf{a}-\mathbf{b}$ shown to efficiently mediate the hydroboration of $N, N^{\prime}$-diisopropylcarbodiimide. $\mathbf{1 a}$ and $\mathbf{3} \mathbf{b}$ are also extremely proficient at catalysing the Tishchenko reaction (100 equivalents $<10 \mathrm{~min}$ ) and $\mathbf{1} \mathbf{a}-\mathbf{b} / \mathbf{3} \mathbf{a}-\mathbf{b}$ all react stoichiometrically with phenylacetylene. Comparing this reactivity with other magnesium hydrides draws mixed conclusions. 1a and $3 \mathbf{b}$ catalyse the hydroboration of $N, N^{\prime}$-diisopropylcarbodiimide significantly faster than the $\mathrm{Mg}-\mathrm{H}$ dimer $\mathbf{A}$, but unlike $\mathbf{A}$ they show no reactivity towards alkenes. The monomeric $\mathrm{Mg}-\mathrm{H}$ B can catalyse both the hydroboration of carbodiimides and the hydrosilation of styrene at room temperature. The rapid reactivity of $\mathbf{3} \mathbf{b}$ towards the Tishchenko reaction is the first example of a $\mathbf{M g}-\mathbf{H}$ acting as a pre-catalyst, indeed $\mathbf{3 a}$ and $\mathbf{A}$ do not lead to any aldehyde dimerization product. This curious pattern in reactivity warrants further comment. The reduced reactivity of $\mathbf{1 b} / \mathbf{3 b}$ versus $1 \mathbf{a} / \mathbf{3 a}$ is undoubtably due to the increase in steric bulk, which rather than rendering complexes $\mathbf{1 b} / \mathbf{3 b}$ monomeric restricts access of the substrate to the metal centre. In fact, DOSY experiments indicate that the less sterically hindered $\mathbf{3 a}$ has more monomeric character in solution than $\mathbf{3 b}$. The steric bulk of these amidinate complexes appears to protect the dimeric magnesium hydride core more efficiently than the 2,6diisopropylphenyl $\beta$-diketiminate ligand in $\mathbf{A}$, hence no reactivity is observed with alkenes. However, when reacted with coordinating substrates, such as $N, N^{\prime}$-diisopropylcarbodiimide or benzaldehyde, a marked increase in reactivity is observed versus the $\beta$-diketiminate system, suggesting that once aggregation is broken the $\mathrm{Mg}$ centre is more accessible. The 4-membered versus 6-membered ligand-metal coordination environment facilitates this increased reactivity, however, some experimental observations also suggest that the more strained ring system makes the complexes less stable. Overall, these results highlight the importance of easy access of the reactive $\mathrm{Mg}-\mathrm{H}$ core and suggest that monomeric magnesium hydrides, such as $\mathbf{B}$, will continue to display superior catalytic capability than complexes with more aggregated structures.

\section{Conflicts of interest}

There are no conflicts to declare.

\section{Acknowledgements}

The Ramsay Memorial Trust and UCL Chemistry are thanked for their financial support. Prof. Claire Carmalt is thanked for her support and mentorship. Dr Jeremy Cockcroft and Richard Kong are thanked for useful XRD discussions.

\section{Notes and references}

1 M. S. Hill, D. J. Liptrot and C. Weetman, Chem. Soc. Rev., 2016, 45, 972-988.

2 D. Mukherjee and J. Okuda, Angew. Chem., Int. Ed., 2018, 57, 1458-1473.

3 S. Harder, Chem. Commun., 2012, 48, 11165-11177.

4 S. J. Bonyhady, S. P. Green, C. Jones, S. Nembenna and A. Stasch, Angew. Chem., Int. Ed., 2009, 48, 2973-2977.

5 M. Arrowsmith, T. J. Hadlington, M. S. Hill and G. KociokKöhn, Chem. Commun., 2012, 48, 4567-4564.

6 M. D. Anker, M. S. Hill, J. P. Lowe and M. F. Mahon, Angew. Chem., 2015, 127, 10147-10149.

7 M. Rauch, S. Ruccolo and G. Parkin, J. Am. Chem. Soc., 2017, 139, 13264-13267.

8 S. Schnitzler, T. P. Spaniol, L. Maron and J. Okuda, Chem. Eur. J., 2015, 21, 11330-11334.

9 M. Arrowsmith, B. Maitland, G. Kociok-Köhn, A. Stasch, C. Jones and M. S. Hill, Inorg. Chem., 2014, 53, 1054310552.

10 A. K. Maity, S. Fortier, L. Griego and A. J. Metta-Magaña, Inorg. Chem., 2014, 53, 8155-8164.

11 A. K. Maity, J. Murillo, A. J. Metta-Magaña, B. Pinter and S. Fortier, J. Am. Chem. Soc., 2017, 139, 15691-15700.

12 B. Freitag, J. Pahl, C. Färber and S. Harder, Organometallics, 2018, 37, 469-475.

13 C. N. de Bruin-Dickason, T. Sutcliffe, C. A. Lamsfus, G. B. Deacon, L. Maron and C. Jones, Chem. Commun., 2018, 54, 786-789.

14 S. J. Bonyhady, C. Jones, S. Nembenna, A. Stasch, A. J. Edwards and G. J. McIntyre, Chem. - Eur. J., 2009, 16, 938-955.

15 R. Lalrempuia, A. Stasch and C. Jones, Chem. - Asian J., 2014, 10, 447-454.

16 H. Xie, X. Hua, B. Liu, C. Wu and D. Cui, J. Organomet. Chem., 2015, 798, 335-340.

17 L. Fohlmeister and A. Stasch, Chem. - Eur. J., 2016, 22, 10235-10246.

18 L. E. Lemmerz, D. Mukherjee, T. P. Spaniol, A. Wong, G. Ménard, L. Maron and J. Okuda, Chem. Commun., 2019, 55, 3199-3202.

19 L. Garcia, M. F. Mahon and M. S. Hill, Organometallics, 2019, 38, 3778-3785.

20 D. J. Gallagher, K. W. Henderson, A. R. Kennedy, C. T. O'Hara, R. E. Mulvey and R. B. Rowlings, Chem. Commun., 2002, 376-377.

21 M. Wiesinger, B. Maitland, H. Elsen, J. Pahl and S. Harder, Eur. J. Inorg. Chem., 2019, 2019, 4433-4439. 
22 S. Schnitzler, P. Cui, T. P. Spaniol and J. Okuda, Dalton Trans., 2017, 46, 1761-1765.

23 C. Weetman, M. S. Hill and M. F. Mahon, Chem. - Eur. J., 2016, 22, 7158-7162.

24 L. Garcia, C. Dinoi, M. F. Mahon, L. Maron and M. S. Hill, Chem. Sci., 2019, 10, 8108-8118.

25 M. Arrowsmith, M. R. Crimmin, M. S. Hill, S. L. Lomas, D. J. MacDougall and M. F. Mahon, Organometallics, 2013, 32, 4961-4972.
26 M. Magre, B. Maity, A. Falconnet, L. Cavallo and M. Rueping, Angew. Chem., Int. Ed., 2019, 58, 7025-7029.

27 A. D. Bage, T. A. Hunt and S. P. Thomas, Org. Lett., 2020, 22, 4107-4112.

28 B. M. Day, W. Knowelden and M. P. Coles, Dalton Trans., 2012, 41, 10930-10934.

29 R. J. Schwamm, B. M. Day, N. E. Mansfield, W. Knowelden, P. B. Hitchcock and M. P. Coles, Dalton Trans., 2014, 43, 14302-14314. 